\title{
SIMULASI AUTOMATIC TRANSFER SWITCH DAN AUTOMATIC MAINS FAILURE DENGAN PLC OMRON SYSMAC CP1E
}

\author{
Suhanto ${ }^{1, a}$ \\ ${ }^{1}$ Prodi D3 Teknik Listrik Bandara Politeknik Penerbangan Surabaya, Indonesia \\ anadiafather@gmail.com
}

\begin{abstract}
Abstrak.
Catu daya listrik merupakan kebutuhan utama peralatan di Bandar Udara, oleh karena itu kehandalan suplai catu daya menjadi prioritas utama untuk menunjang pelayanan jasa penerbangan. Selain PLN sebagai catu daya utama Genset digunakan untuk suplai catu daya cadangan. Diperlukan sistem kendali Automatic Transfer Switch (ATS) dan Automatic Mains Failure (AMF) untuk mengatur peralihan catu daya dari PLN ke Genset atau sebaliknya. Sistem kendali ATS dan AMF menggunakan PLC Omron Sysmac CP1E dengan tampilan menggunakan Easy Builder 8000 dari Weintek yang berfungsi sebagai kendali dan monitor ATS dan AMF. Hasil pengujian pada ATS dan AMF pada mode manual dan otomatis, sistem berjalan dengan baik.
\end{abstract}

Kata kunci. Automatic Transfer Switch (ATS), Automatic Mains Failure (AMF), PLC

\begin{abstract}
.
Electric power supply is the main requirement of equipment at the airport, therefore the reliability of the supply of power supplies is a top priority to support flight services. In addition to PLN as the main power supply the generator is used to supply a backup power supply. Automatic Transfer Switch (ATS) and Automatic Mains Failure (AMF) control systems are needed to regulate the switching of power supplies from PLN to Genset or vice versa. The ATS and AMF control systems use the Omron Sysmac CPIE PLC with a display using Easy Builder 8000 from Weintek which functions as an ATS and AMF monitor and control. Test results on ATS and AMF in manual and automatic modes, the system runs well.
\end{abstract}

Keywords. Automatic Transfer Switch (ATS), Automatic Mains Failure (AMF), PLC

\section{PENDAHULUAN}

Untuk menunjang pelayanan jasa penerbangan di Bandar Udara diperlukan catu daya listrik yang handal baik utama atau cadangan berupa Genset. Sistem kendali transfer switch catu daya dan kendali Genset menggunakan PLC Omron Sysmac CP1E, menggunakan PLC dimaksudkan untuk menggantikan kontrol relai yang tidak fleksibel, pengkabelannya lebih banyak ,dan pengubahan sistemnya relatif lebih sulit serta biaya maintanance yang relatif lebih mahal. Sebagai tampilan sistem kendali digunakan Easy Builder 8000 dari Weintek yang digunakan untuk kendali Automatic Transfer Switch (ATS) dan Automatic Mains Failure (AMF).

\section{METODOLOGI PENELITIAN}

Berdasarkan pada blok diagram dibawah, sistem transfer catu daya ke beban dari PLN ke Genset atau sebaliknya dapat dilakukan dengan mode manual atau otomatis yang dapat kendalikan dan dipantau dari personel komputer dengan tampilan Graphic User Interface, sistem kendali ATS dan AMF menggunakan PLC Omron tipe SYSMAC CP1E. 


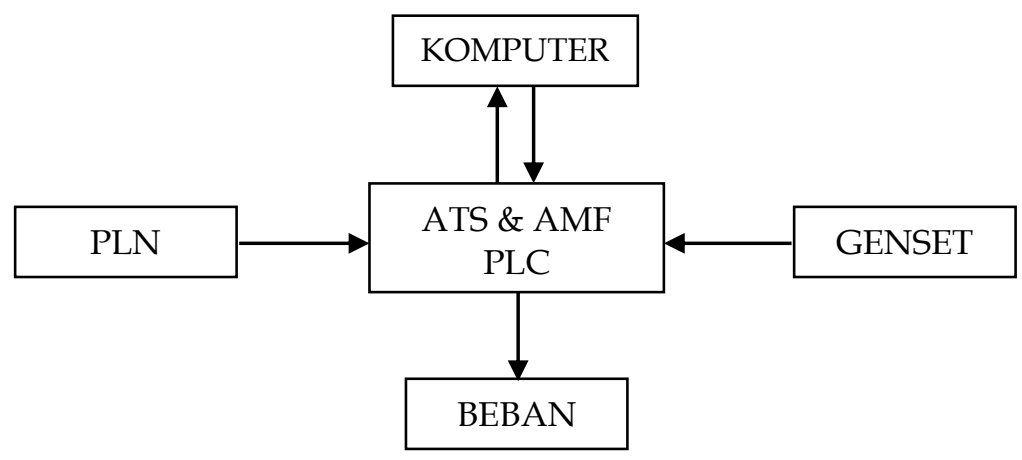

Gambar 1. Blok Diagram Simulasi

\section{Alamat Input dan Output PLC}

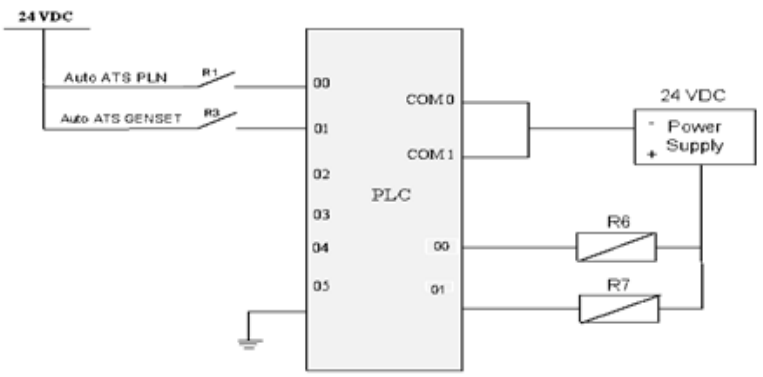

(a)

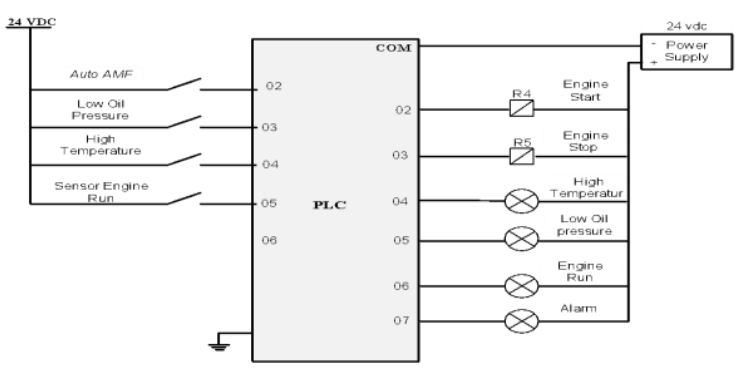

(b)

Gambar 2. (a) Input dan Output ATS, (b) Input dan output AMF

Sebelum membuat program ladder terlebih dahulu ditentukan alamat input dan output PLC untuk memudahkan penentuan alamat PLC dan komponen yang menjadi input dan outputnya.

Tabel 1. Alamat Input dan Output ATS dan AMF

\begin{tabular}{|l|l|l|l|}
\hline No & Komponen ATS & $\begin{array}{l}\text { Keteranga } \\
\text { n }\end{array}$ & Alamat \\
\hline 1 & Selector Switch Auto K1 & Input & 00 \\
\hline 2 & Selector Switch Auto K2 & Input & 01 \\
\hline 3 & Relai ke Kontaktor 1 & Output & 00 \\
\hline 4 & Relai ke Kontaktor 2 & Output & 01 \\
\hline No & Komponen AMF & Keterangan & Alamat \\
\hline 1 & Selector Switch Auto AMF & Input & 02 \\
\hline 2 & Sensor High Temperature & Input & 03 \\
\hline 3 & Sensor Low Oil Pressure & Input & 04 \\
\hline 4 & Sensor Engine Run & Input & 05 \\
\hline 5 & Relai Engine Start & Output & 02 \\
\hline 6 & Relai Engine Stop & Output & 03 \\
\hline 7 & Lampu Indikator High Temperature & Output & 04 \\
\hline 8 & Lampu Indikator Low Oil Pressure & Output & 05 \\
\hline 9 & Lampu Indikator Engine Run & Output & 06 \\
\hline 10 & Alarm & Output & 07 \\
\hline
\end{tabular}




\section{Diagram Ladder ATS Mode Otomatis}

Berdasarkan ladder dibawah 0.00 adalah input berupa selector switch yang mengaktifkan kontak point auto PLN. Jika input 0.00 aktif maka TIM 000 akan aktif. TIM 000 akan mengaktifkan kontak T000 yang terhubung dengan koil W0.06 sehingga Circuit Breaker (CB) PLN akan energize

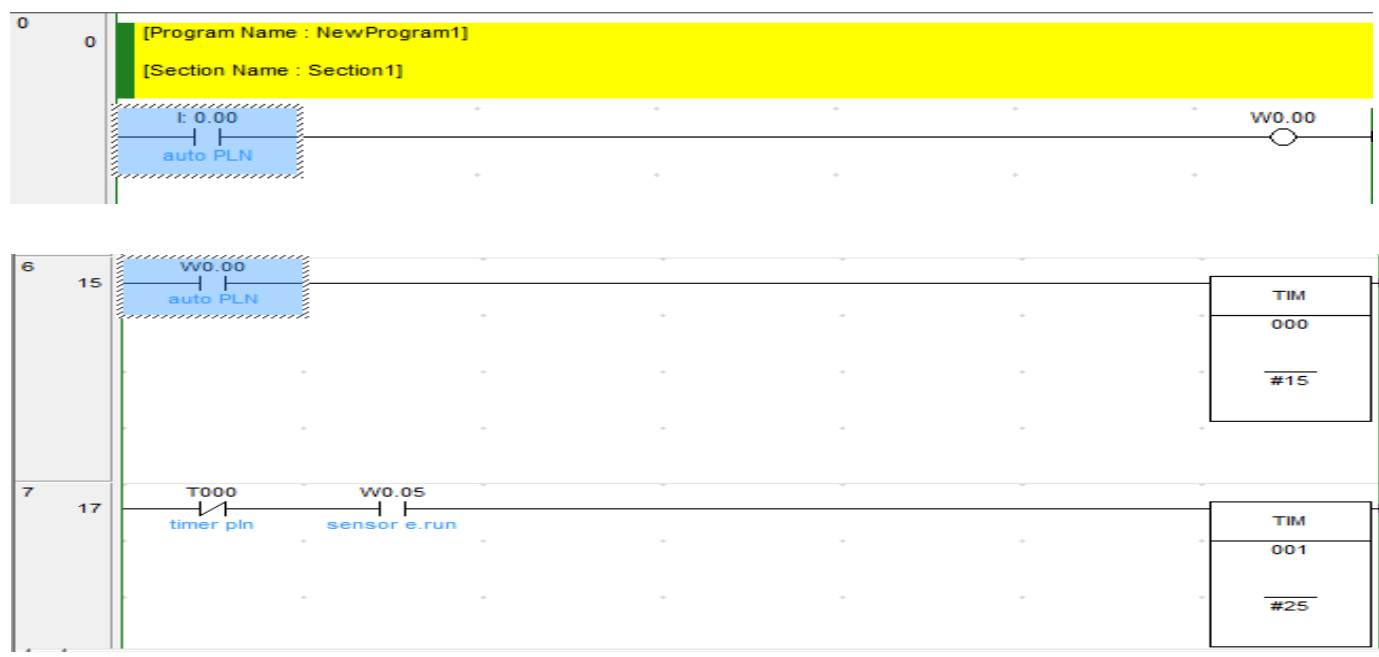

Gambar 3. Diagram Ladder Otomatis PLN On

\section{Diagram Ladder AMF Genset Start Otomatis}

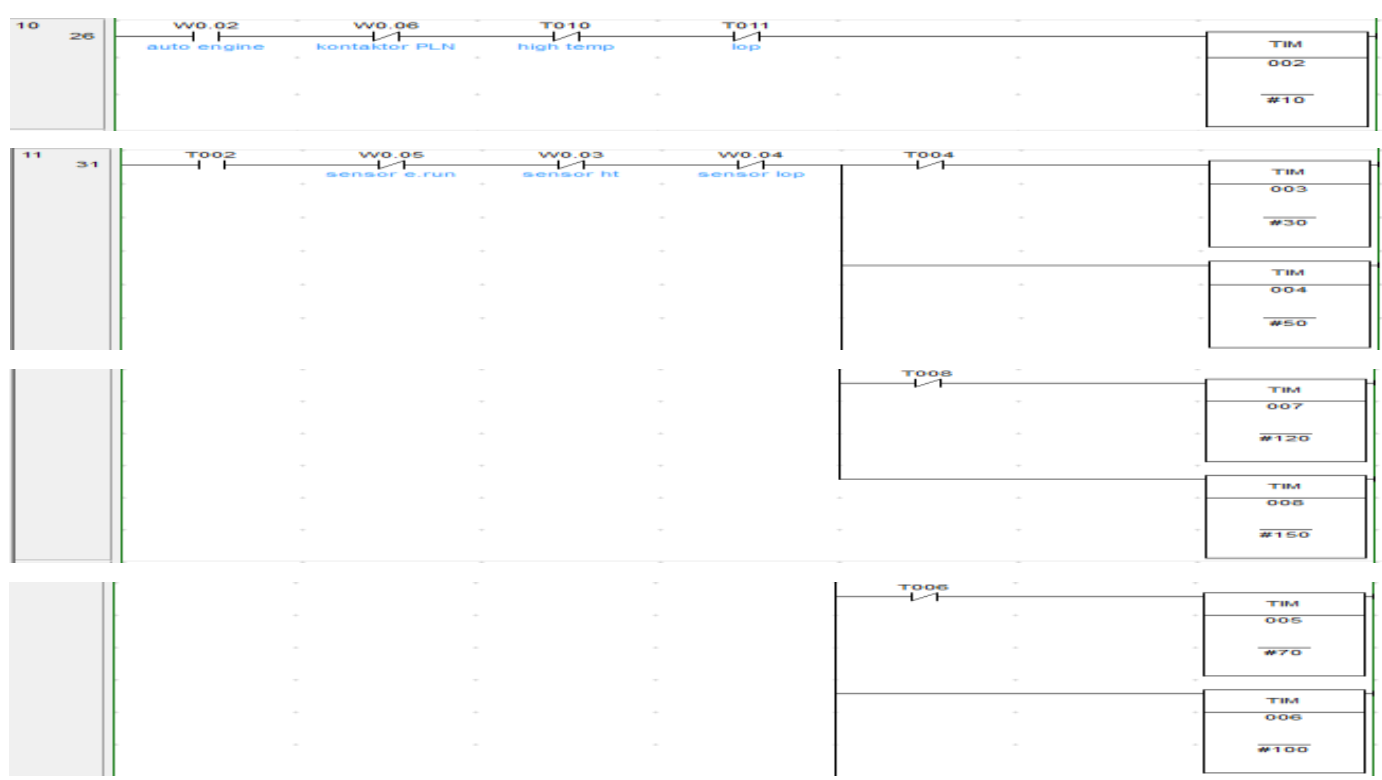

Gambar 4. Posisi Otomatis Genset Start

Jika sensor tegangan 0.00 auto PLN mati T002 melakukan starting engine sebanyak 3 kali pada koil W0.09 terhubung dengan starter engine. Apabila sebelum 3 kali starting engine sudah running akan terbaca oleh sensor engine run yang kemudian menghentikan proses start engine. 


\section{Diagram Ladder Gangguan Genset (Low Oil Pressure, High Temperatur)}

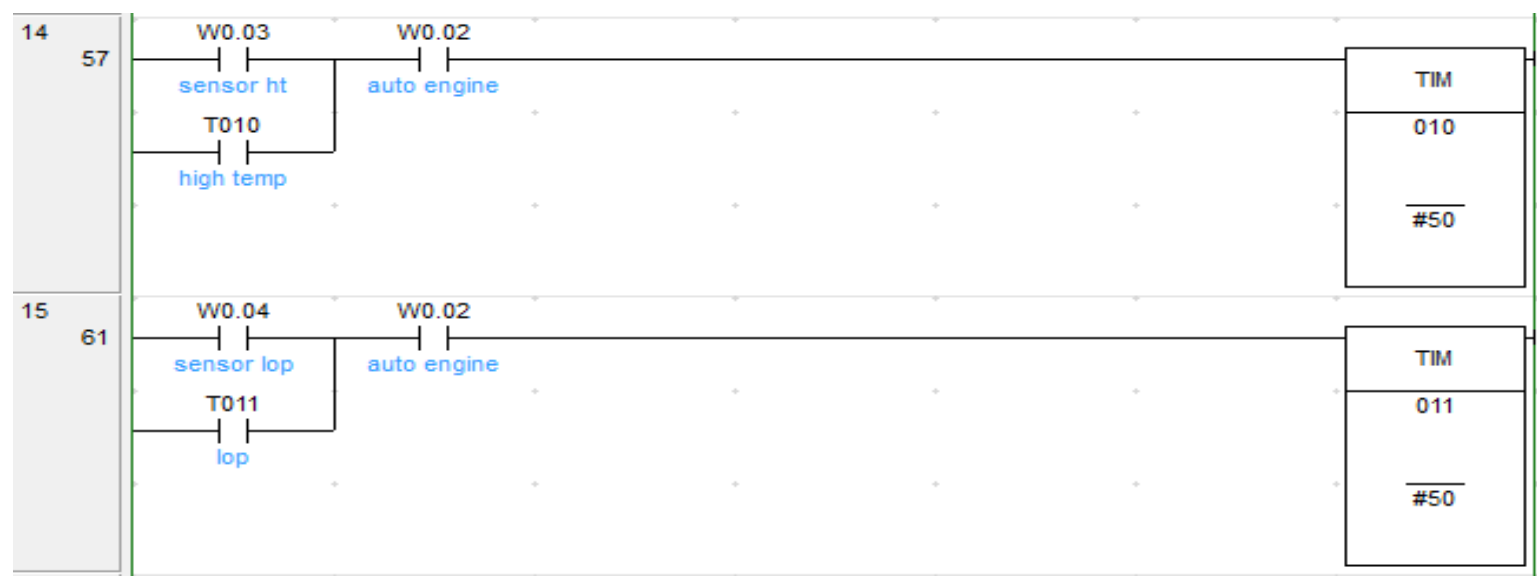

Gambar 3.13 Posisi Gangguan Genset

Sumber : Hasil Karya Penulis(2014)

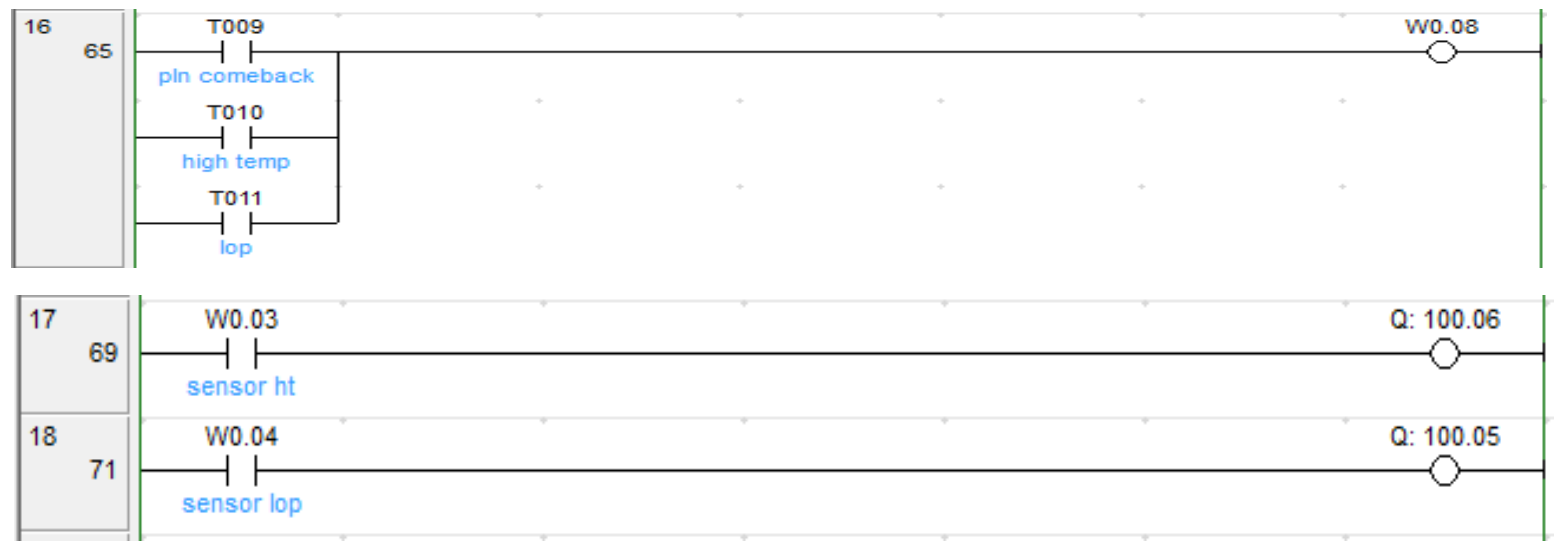

Gambar 5. Diagram Ladder Gangguan Engine

Jika genset mengalami gangguan Low Oil Pressure (LOP), sensor LOP akan memberikan sinyal pada input W0.04 kemudian mengaktifkan TIM 011 kontak point T011 mengaktifkan koil W0.08 yang terhubung dengan relai engine stop untuk mematikan mesin genset.

\section{HASIL, PEMBAHASAN DAN ANALISA}

\section{Rangkaian ATS dan AMF}

Untuk pengujian rangkaian ATS dan AMF akan dilakukan dilakukan mode manual dan otomatis. Berikut ini adalah gambar rangkaian ATS dan AMF secara keseluruhan: Komponen yang digunakan 2 (dua) kontaktor, 3 (tiga) relai $220 \mathrm{Vac}, 4$ (empat) relai $24 \mathrm{Vdc}$ dan 1 (satu) Programmable Logic Controller. 


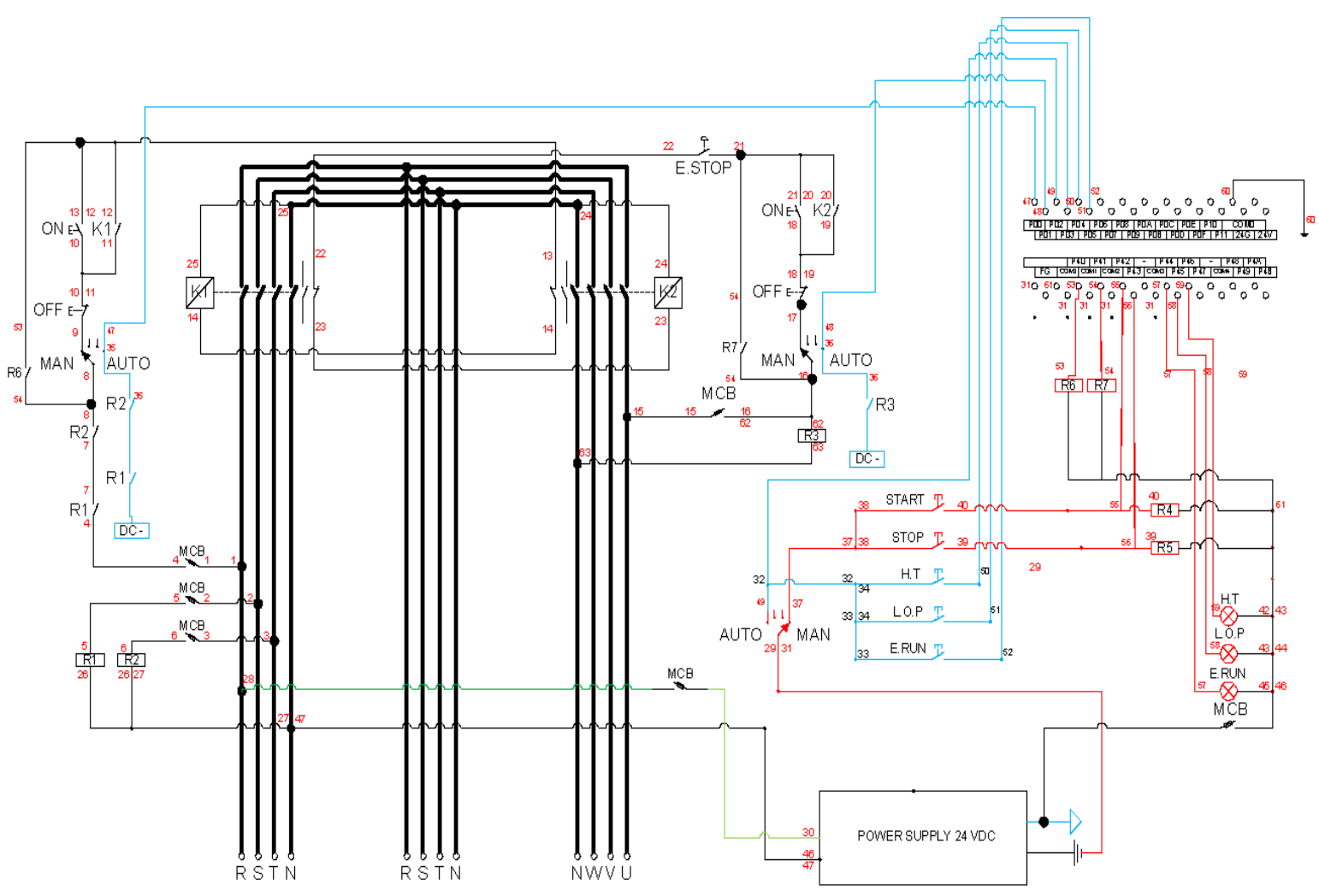

Gambar 6. Wiring Diagram Simulasi ATS dan AMF

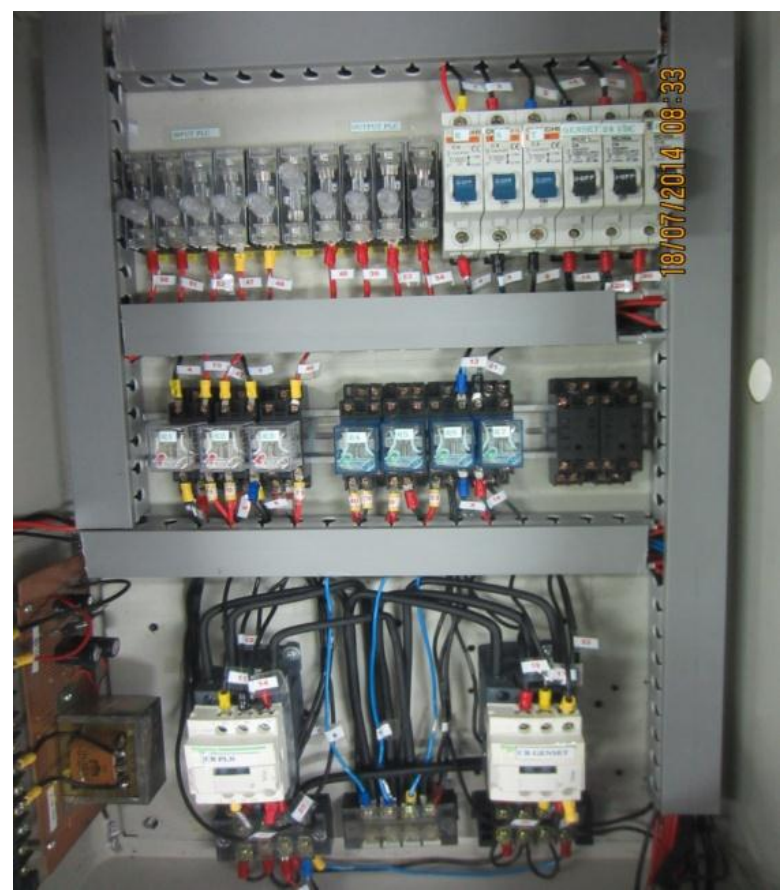

Gambar 7. Tampilan Panel Simulasi ATS dan AMF

\section{Pengujian Rangkaian ATS dan AMF Mode Manual}

Dilakukan pengujian ATS dan AMF secara manual meliputi pengujian CB PLN, CB Genset, Start Engine, Stop Engine dengan menggunakan push button yang ada di panel. Hasil pengujian bekerja dengan baik sesuai dengan tabel dibawah ini. 
Tabel 2. Pengujian Rangkaian ATS dan AMF Secara Manual

\begin{tabular}{|l|l|l|l|l|l|l|l|l|l|l|}
\hline No & Uraian & K1 & K2 & R1 & R2 & R3 & R4 & R5 & R6 & R7 \\
\hline 1 & ATS Manual CB PLN Aktif & On & Off & On & On & Off & Off & Off & Off & Off \\
\hline 2 & $\begin{array}{l}\text { ATS Manual CB Genset } \\
\text { Aktif }\end{array}$ & Off & On & On & On & On & Off & Off & Off & Off \\
\hline 3 & $\begin{array}{l}\text { AMF Manual Start Engine } \\
\text { Aktif }\end{array}$ & Off & Off & On & On & On & On & Off & Off & Off \\
\hline 4 & $\begin{array}{l}\text { AMF Manual Stop Engine } \\
\text { Aktif }\end{array}$ & Off & Off & On & On & On & Off & On & Off & Off \\
\hline
\end{tabular}

\section{Pengujian Rangkaian ATS dan AMF Secara Otomatis}

Pada tabel dibawah dilakukan pengujian secara otomatis terhadap ATS dan AMF yaitu CB PLN dan Genset, star dan stop engine saat PLN Off dan gangguan mesin Genset berupa low oil pressure dan high temperature. Dari hasil pengujian komponen K1, K1 dan R1-R7 bekerja dengan normal dan baik.

Tabel 3. Pengujian Rangkaian ATS dan AMF Secara Otomatis

\begin{tabular}{|l|l|l|l|l|l|l|l|l|l|l|}
\hline No & Uraian & K1 & K2 & R1 & R2 & $\mathbf{R 3}$ & $\mathbf{R 4}$ & $\mathbf{R 5}$ & R6 & R7 \\
\hline 1 & ATS CB PLN Aktif & On & Off & On & On & Off & Off & Off & On & Off \\
\hline 2 & ATS CB Genset Aktif & Off & On & Off & Off & On & On & Off & Off & On \\
\hline 3 & AMF Start Engine Aktif & Off & Off & Off & Off & On & On & Off & Off & On \\
\hline 4 & $\begin{array}{l}\text { AMF Stop Engine Aktif } \\
5\end{array}$ & Off & Off & On & On & Off & Off & On & On & Off \\
\hline 6 & $\begin{array}{c}\text { AMF High Temperature } \\
\text { Aktif }\end{array}$ & On & Off & Off & Off & On & Off & On & Off & Off \\
\hline \begin{tabular}{l} 
Aktif Low Oil Pressure \\
\hline
\end{tabular} & On & Off & Off & Off & On & Off & On & Off & Off \\
\hline
\end{tabular}

Selain melakukan pengujian ATS dan AMF dilakukan pengujian tampilan dan komunikasi serial RS-232 yang termasuk salah satu bentuk konfigurasi pada komunikasi HLC (Host Link Communication), setelah dilakukan pengujian tampilan bekerja dengan baik.

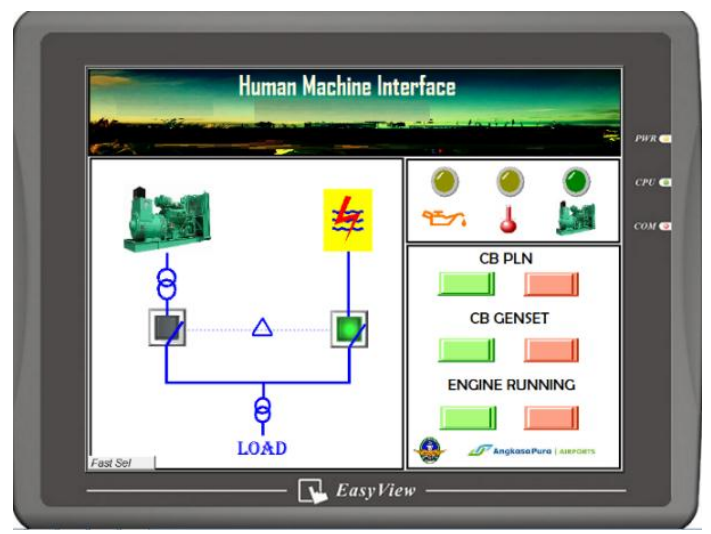

Gambar 8. Pengujian Tampilan CB PLN ON 


\section{KESIMPULAN}

1. Sistem ini memiliki tingkat kehandalannya lebih baik dari sistem kontrol yang ada karena pengkabelannya lebih ringkas dan pencarian troubleshooting lebih mudah.

2. Tampilan menggunakan Easy Builder memudahkan pengguna untuk memantau sistem kendali ATS dan AMF.

\section{DAFTAR PUSTAKA}

1. Bishop, Owen, 2004, Dasar - Dasar Elekronika. Erlangga. Jakarta

2. Dr. Ir Adriansyah, Andi. Pengantar Sistem Kontrol.

3. Jack, Hugh. 2008, Automating Manufacturing Systems.

4. Omron, 2003,Sysmac CPM1A Programmable Controller: Operation Manual, Omron, Japan.

5. Setiawan, Iwan, 2006. Programmable Logic Controller Dan Teknik Perancangan Sistem Kontrol, Penerbit Andi Yogyakarta

6. Anggraini, L., \& Laksono, A. B. (2019). Pemodelan dan Analisa Struktur Mekanika pada Kontrol Sistem Adaptif End Effector dengan Dynamixel AX-18A Motor Servo. Journal of Mechanical Engineering and Mechatronics, 3(1), 1-12. 